\title{
On the Reaction of Leaves to Traumatic Stimulation.
}

\author{
BY \\ F. FROST BLACKMAN, M.A., D.SC., \\ Lecturer on Botany in the University of Cambridge, \\ AND \\ GABRIELLE L. C. MATTHAEI, \\ Bathurst Student, Nerwham College.
}

With Plate XXIX, and five Figures in the Text.

$\mathrm{T}$ the course of the experiments on respiration which we 1 have been carrying on for some time, we have come across some interesting phenomena connected with the reaction of leaves to experimentally produced injuries. We have followed these out to a certain extent and propose to give now an account of the results.

The vitality of cut-off leaves, kept in the dark but supplied with water, is considerable and much beyond general expectation. Leaves of Cherry-Laurel remain healthy for perhaps fifty days in such conditions, and leaves of Oleander have been kept thus for several months without ever having a chance of obtaining any fresh carbon-nutriment. The behaviour of the respiration under these conditions we shall treat of elsewhere: here it may be noted that Oleander leaves invariably put out vigorous crops of adventitious roots from the stump of the leaf-stalk under these conditions, and that [Annals of Botany, Vol. XV. No. LIX. September, rgor.] 


\section{Blackman and Matthaei.-On the Reaction of}

removal of the roots may be followed by a second crop and even a third. Cherry-Laurel leaves, however, never produce roots, but they develop a callus from the cut surface of the leaf-stalk which forms a well-marked pad over it.

Such recuperative processes indicate considerable vitality, but the remarkable activity of the leaf that can be induced by injury even after some weeks of starvation shows that the leaf is really in full vigour.

We will confine ourselves in this paper to the case of the Cherry-Laurel (Prumus Laurocerasus, garden var. rotundifolia), and at first to its behaviour when the leaves used are such as have been cut off and are being kept in the laboratory in a beaker, with the cut stalks in water. A very loose lid is placed on the vessel so that the air surrounding the leaves is kept moist. If patches of cells of these leaves be killed-and this conveniently becomes evident by their turning brown very quickly - the surrounding sound tissues always react by cutting off and exfoliating the injured patch, so that it drops, without any external assistance right out of the leaf, and a hole results. The line of exfoliation follows the outline of the injury with some precision but at a certain distance from it, and so any number of holes of any desired outline can be brought about; the leaves $2,3,5,6$, in Plate XXIX, are bizarre examples of the effect.

The healing of wounded leaves has been previously described for several cases, but we can find no description of the process of exfoliation which we have observed, and of which we may now give a detailed account.

I.

If a clean cut be made through the substance of a CherryLaurel leaf with a sharp knife no healing reaction follows. In ever so many cases ten or more incisions have been made in each half of the lamina, at right angles to the midrib and extending from the midrib right to the edge of the leaf. A leaf thus cut into some twenty segments, united only by means of the midrib, will if protected from too great dryness 
in the way that we have indicated remain alive, healthy, and turgid for a month or more, although all the intercellular spaces are thus thrown into uncontrolled communication with the external air. The cells that are actually cut through of course die and some three layers of adjacent cells may perish but never a sufficient number to produce a brown edge visible to the naked eye.

If, on the contrary, a sufficient number of cells be killed to produce a visible brown margin to the cut, then the cutting-out reaction will follow. All the methods of killing tried, including rupturing the cells by a heavy blow, and contact with a hot iron, provoke the same reaction. The neatest method that we have employed, now to be described, may seem a rather indirect one, but we were led to it in the course of our respiration experiments. If a leaf, cut in any way, be injected with water under the air-pump, and if afterwards for a few minutes the water be rapidly dried out of it-as in vacuum-then the cells all round the edges of the cuts are disorganized and killed and quickly turn brown for a distance of one to three millimetres according to the duration of the treatment. The brown margin that results is fairly uniform all over any given leaf and the cutting-out reaction follows with certainty.

The first sign of the reaction is visible five or six days after the leaves have been put back in a vessel with their stalks in water; at least this holds good for experiments made in April, May, and June at laboratory temperatures. This indication consists of a fine sharp line running all round the dead region at a distance of one to three millimetres. When the leaf is viewed against the light, this line is seen to be quite translucent and strongly contrasted against the rest of the opaque lamina.

On cutting sections, at the first glance there appeared to be no internal corresponding change, but it was soon seen that the spongy parenchyma in the track of the line had grown and divided so as to entirely block the intercellular spaces and so had produced a local translucency, just like that produced by filling up the intercellular spaces of a leaf with water. 


\section{Blackman and Matthaei.-On the Reaction of}

The fourth of the photographs in Plate XXIX shows this stage, but only as seen by reflected light, when the line is not nearly so obvious. In the photograph there can be distinguished (I) the original cuts between the leaf-veins made with a sharp knife, (2) the brown fringes round the edges of the cuts produced by cells that have been killed by rapid drying, and (3) the fine sharp occlusion-line running round each killed area.

After a few more days the epidermis on both surfaces of the leaf will be found to be cleanly split through, all along the track of the line. The splitting extends steadily through the substance of the mesophyll and in another week or two the separation will be complete, the circumscribed areas will drop out, and leave such a leaf as is shown in the fifth photograph - a perfectly healthy leaf which has thrown off all the dead portions and has its edges closed in again all round.

We have worked out roughly the histology of the separationprocess by cutting sections through the lamina at right angles to the track of the translucent line. An absciss-layer arises

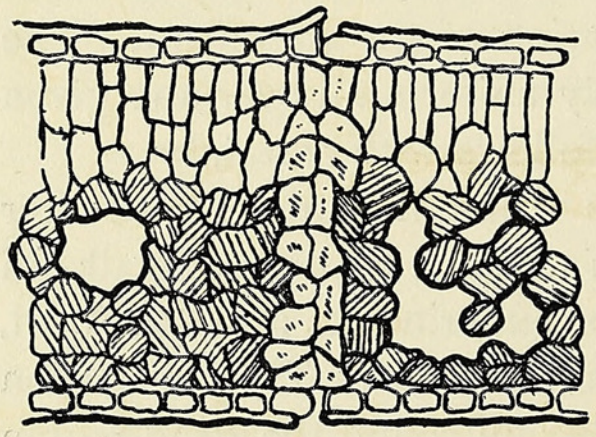

Fig. 4 . by the division of a single row of cells running from one epidermis to the other through the occluded spongy parenchyma and the palisade-tissue. As soon as the cells along this row have divided into two the cuticle seems to crack sharply across and the contiguous epidermis-cells in the region of the line become separated from one another without themselves taking any part in the division. Fig. 4, which is rather schematic, shows this stage, and it is to be noticed as a constant character that the absciss-layer does not form in the middle of the solid occluded portion of mesophyll, but always on the side towards the dead cells.

The new cells of the absciss-layer are poor in cell-contents, and the two layers of cells soon round off and so separate 
from one another (Fig. 5), till the two portions of leaf are quite free. No further histological change takes place in the piece of leaf that falls off, but on the edge belonging to the main leaf these new cells go on multiplying parallel to the new edge, till we get the appearance of a meristem with a number of tiers of swollen cells beyond, generated by its activity and giving theedgea velvetylook. These

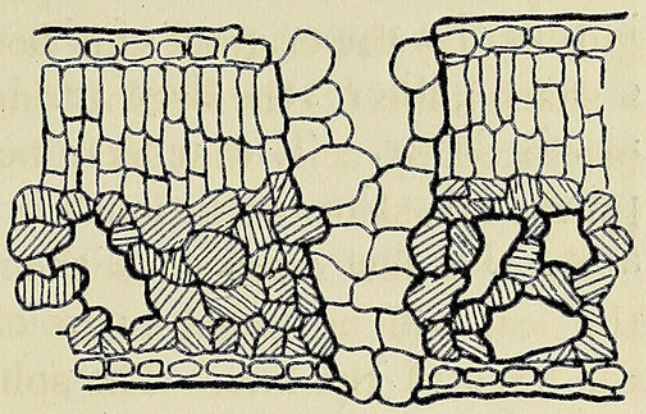

Fig. 5. cells have very thin walls but are cuticularized. Fig. 6 is made from a preparation in strong sulphuric acid; the mesophyll has all been dissolved and the cuticularized pad of callus-like cells is seen to be attached to the cuticle at both surfaces of the leaf, so as to close in and protect the mesophyll as effectually as before.

Some instructive variations of the cutting-out process must now be

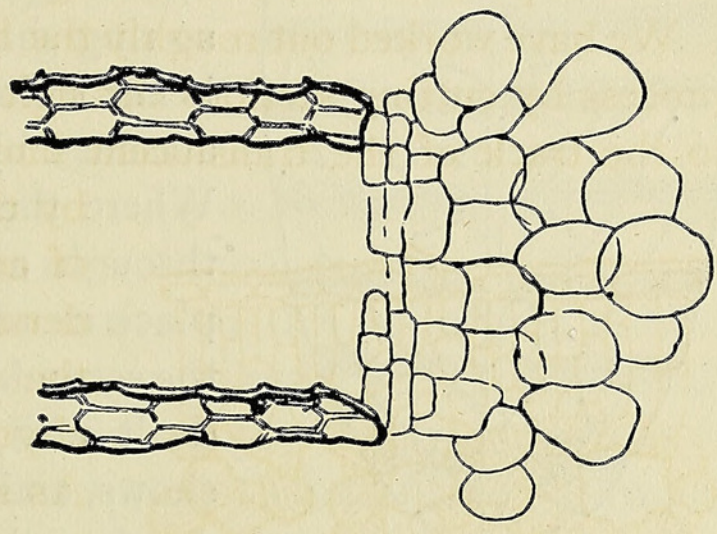

Fig. 6. considered. If a number of dead areas be produced close together there may not be sufficient sound tissue between them for the line of occlusion and the absciss-layer to be formed at the proper distance from the dead cells. The line of demarcation then sweeps round and includes several contiguous dead areas in one contour.

The first photograph (Plate XXIX) shows a good case of this, as a line of occlusion envelops seven parallel strips of dead tissue and only attempts to pass between the upper two which are rather further apart. The second photograph shows the same leaf at a later stage with the whole patch of living 


\section{Blackman and Matthaei.-On the Reaction of}

and dead tissue nearly exfoliated in one large piece. In the third photograph those circular dead patches which are well separated are each surrounded with an effective absciss-layer, but in the upper part of the leaf four such dead spots are close together and they are being cut out by one common absciss-layer. The appearance of this leaf is rather complicated by the large round hole in the middle of each dead area. In this case, circular areas of cells were killed by

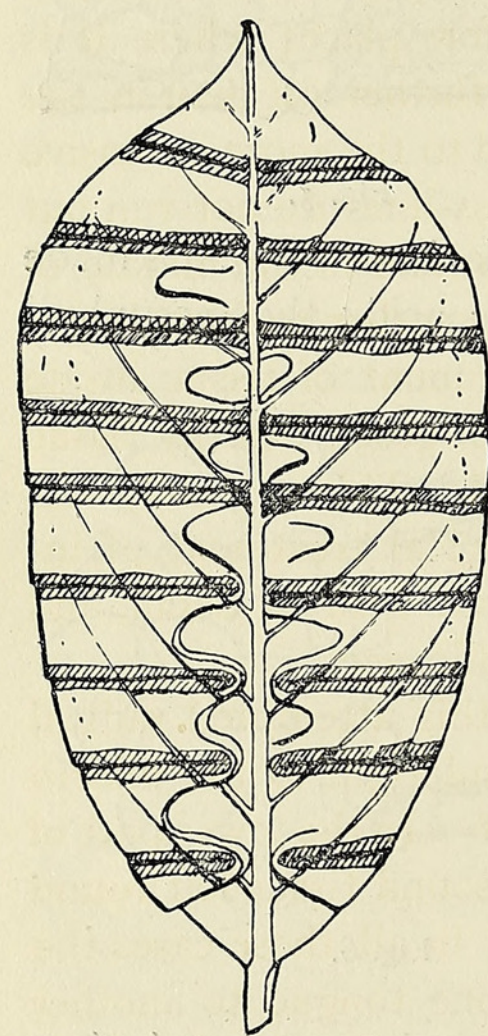

Fig. 7 . a round piece of hot iron, and subsequently, but this is of no present significance, the centres of these were removed by a cork-borer of smaller diameter than the piece of iron. The circular absciss-layer is formed in the sound tissue round the patch and so ring-shaped stretches of tissue are being exfoliated, and are at present attached by one or two points only. Where the absciss-layer has to pass through a vein the processes take place more slowly, but the largest of the secondary veins may be effectively dealt with, as the sixth photograph shows, and in this also the pieces are dropping out. We have not observed any case of the absciss-layer succeeding in passing through the midrib. It follows then that if a strip of dead cells extends across the leaf from the edge right up to the midrib it cannot be completely surrounded with an absciss-layer and thrown off. It becomes interesting to see what reaction will then take place.

The leaf shown diagrammatically in Fig. 7 furnishes a case in point, and it merits detailed consideration. The lamina was cut and the marginal cells killed by rapid drying as in the other cases, but the treatment was more prolonged, and very broad dead brown margins border all the cuts. In the 
upper part of the leaf these dead strips extend right to the midrib, but in the lower part they just fall short of it. The position of the resulting absciss-layers is shown by the curved black lines, and everywhere, even in the upper part where they outline isolated tongues, one in each sound compartment of the leaf, the actual separation of tissues has taken place as definitely as if produced by a sharp scalpel.

Here the absciss-line no longer runs a parallel course with the edges of the dead area. In the few places where it is approximately parallel it stands much further off than in the previous cases, which we think is related to the more extensive injury. Except at one point the absciss-lines do not run out to the edge of the leaf, but they curve round in the middle of the sound strips of tissue and join one another to form larger or smaller tongues, retaining a small amount of tissue inside their curves and leaving large masses of green healthy tissue outside to be exfoliated with the dead. This certainly has the appearance of being a radical surgical treatment of injuries which are too extensive to be dealt with in detail, and we believe it really has this sort of significance.

In the upper part of the leaf even this attempted radical cure fails, because the dead strips extend right to the midrib and so in no way can they be thrown off. In the lower part of the leaf there are very narrow tracts of sound tissue left round the central ends of the dead strips, and in all these cases the absciss-line extends along them from one tongue to another and so the dead tissue is all cut off, as on the left half, below, though with great sacrifice of sound tissue as well. The leaf, by a continuation of this treatment, would be reduced to a midrib bearing a few almost isolated tongues of sound tissue.

Below the lowest injury the absciss-line makes its way to the edge and a quarter of the leaf is hanging, attached only above.

It is further very interesting to note that where the abscissline passes along the narrow bridges of sound tissue between the successive dead strips and the midrib it has to be formed extremely close to the dead cells, and not at the usual con- 


\section{Blackman and Matthaci.-On the Reaction of}

siderable distance. This indicates again a departure from the usual type of reaction, a special effort-so to speakmade to secure the exfoliation of all these extensive dead masses.

It is difficult to resist the conclusion that the leaf is reacting as an autonomous whole and modifying the usual parallel absciss-line, to suit the special difficulties of its condition. The behaviour of this leaf seems to us to strongly support the view, suggested by the great vitality of these isolated leaves, that the solidarity and autonomy of a single leaf may be considerable.

\section{II.}

All the leaves described above were kept moist in beakers, as has been stated. When leaves attached to the shrub growing in the open were experimented upon, the reaction to incisions was found to

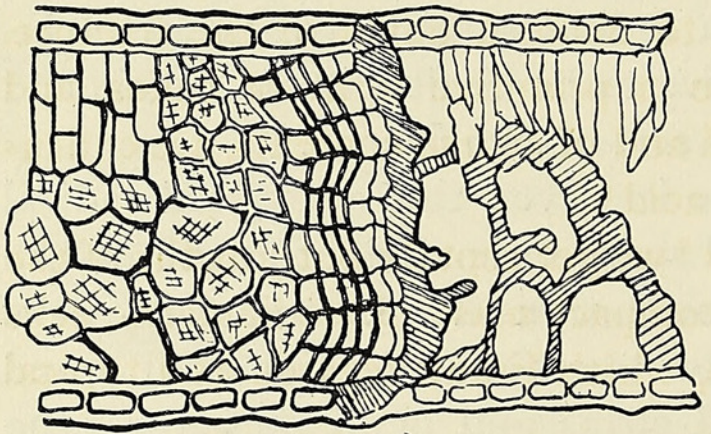

Fig. 8. be quite different, and it never took the form of the exfoliation which we have just described.

If cuts be made with a scalpel through theleaves of Cherry-Laurel, while still on the plant, they quickly become bordered with a very narrow edge of dry brown cells, and in a week or two a translucent line may form parallel and very close to the brown edge of the cut. This is an occlusion-line of normal structure, and a line of active cell-division forms in it on the side towards the cut edge. No trace of separation is found, however, between the daughter-cells that arise from it, but they remain compactly adherent and division is continued, so that a periderm of several layers of cork results, as is shown in Fig. 8.

Let us now turn to the records of previous workers, before we consider the problems that these reactions suggest. There 
is no occasion for us to consider the literature of wound-healing in general, as a good account was given of it by Massart ${ }^{1}$ a few years ago. Confining ourselves to leaves, we find that many different reactions have been observed on leaves in situ as a result of spontaneous, accidental or experimental injuries. Collating the chief papers, those by Bretfeld ${ }^{2}$, Frank ${ }^{3}$, and Massart ${ }^{1}$, we may distinguish at least five different cases, none of them involving formation of an absciss-layer.

(I) In Camellia and in many marsh plants it is said that there is no reaction, and that the killed tissues dry up to form a scar over an injured surface ${ }^{4}$.

(2) In Nuphar and other aquatic plants when the large internal spaces are laid open by injury there takes place a filling up of the lacunae by growth of the cells which border them ${ }^{5}$.

(3) In Leucojum something similar takes place, but the outgrowing cells form long almost unseptate tubes, tightly packed and capable of uniting with the cells growing out from the opposite side of a cut, to make a union of the fracture. Frank considers this to be a primitive form of callus, and the cells, though thin-walled and of sparse contents, are cuticularized and resist sulphuric acid ${ }^{6}$.

(4) In Cormus ${ }^{7}$ and $H_{0 y a^{8}}$ we get septate outgrowths of the mesophyll-cells to form a compact mass of isodiametric cells without intercellular spaces, which Frank regards as a typical callus.

(5) In succulent and in some other leaves several layers of corky cells may arise by division in the mesophyll-cells parallel to the surface of the wound. This takes place in quite the same way as the well-known new formation of cork below the wounded surface of a potato ${ }^{9}$. No increase in bulk of

1 Massart, $\mathrm{La}$ cicatrisation chez les végétaux. Méms. couronnés de l'Acad. roy. de Belgique, T. $57, \mathrm{I} 898$.

${ }^{2}$ Bretfeld, Vernarbung u. Blattfall, Pringsheim's Jahrb., vol. xii, 1879.

${ }^{3}$ Frank, Die Krankheiten der Pflanzen, Breslau, I 895, Bd. i; cf. also the section on the same subject in Schenk, Handbuch der Botanik, Bd. i.

${ }^{4}$ Bretfeld, loc. cit., p. I39.

${ }^{6}$ Frank, loc. cit., p. 65 , Fig. İ̃.

${ }^{8}$ Massart, loc. cit., p. 57 , Fig. 54 .

${ }^{5}$ Massart, loc. cit., p. 4I, Fig. 43 .

7 Frank, loc. cit., p. 67, Fig. I3.

${ }^{9}$ Bretfeld, loc. cit. 


\section{Blackman and Matthaei.-On the Reaction of}

the original cells takes place, only septation, and this is the typical 'wound-cork' of Frank ${ }^{1}$.

(6) The exfoliation by an absciss-layer described by us in Prunus Laurocerasus forms a sixth type of reaction.

Here then we have six modes of reaction, apparently very distinct from one another, yet on reflection there is no doubt that the leaves of the Cherry-Laurel show processes that suggest comparison with each one of them. The absence of structural reaction; the occlusion of spongy parenchyma; the outgrowth of bulging cells at the edge after exfoliation; the development of the solid pad of tissue in which the meristem forms; and the periderm-formation in attached leaves, are five processes, having many points in common with the first five types of reaction respectively. In addition there is also the exfoliation-process.

The variations in the reaction seem to be correlated with the nature of the surrounding conditions, and it is clear that no further progress can be made in sorting-out these different processes without bringing the problems from the field into the laboratory where the conditions can be carefully controlled. For this to be successful, leaves of marked vigour and vitality are essential, and those of the Cherry-Laurel promise well in this respect. We hope to carry further the investigation of the controlling effects of external conditions.

It may be mentioned here that only fully grown leaves have been used in all cases, and as most of the work was done in the early summer, the leaves used were necessarily those of the previous year: in July, however, the newly matured leaves give similar results. Very young leaves possess a considerable power of regenerating lost tissues, as distinguished from the carrying out of mere healing processes, and in them the epidermis may divide as well as the mesophyll and new typical epidermis may be generated. This normally happens with these fenestrated leaves which develop large perforations as they unfold ${ }^{2}$.

1 Frank, loc. cit., p. 60.

${ }^{2}$ Massart, loc. cit., p. 55, Fig. 47, also p. 30. 
Being able to obtain the exfoliation-effect with certainty in the laboratory we have looked out for signs of it in the field, and have seen a number of specimens illustrating it, although it has never occurred in response to our experimental lesions. In natural specimens the green sound tissue on the distal side of the absciss-layer dries up quickly and turns brown before the piece drops out, so that the separation appears to be taking place at the exact edge of a dead patch as if it were only a mechanical rupture between dry and living tissue.

In the laboratory, further, we have occasionally found that leaves which have remained for a long time with their stalks in water may proceed to exfoliate small areas which happen to have become injected with water ; and rarely, small exfoliations take place for which there is no obvious cause. We hope that further experiments will throw light on these cases.

\section{III.}

Finally, we may just touch on two or three problems and give a few tentative reflections that suggest themselves, in relation to the contrasted reactions that have been noted, and to the biological significance of the various processes.

(I) Occlusion of the spaces in a spongy parenchyma would seem to be a necessary preliminary to the formation of a definite line of meristem in that tissue. Is this the whole significance of the occlusion-line, or is the process of direct value as a reparative one, closing in again the internal spaces of the leaf?

Though occlusion has been described as one of the types of wound-healing, yet we incline to the other view here, as it takes place very locally and is closely linked to the subsequent activity, and occurs so well in the leaves kept in damp air, which do not require for their continued sound health to have their spaces occluded at all.

(2) The fact that leaves do not react to a clean incision, which kills only a minimal number of cells, seems to us to be of the first importance. We have several times found that the disorganization of rapid drying may fail to kill an appreciable 


\section{Blackman and Matthaei.-On the Reaction of}

number of cells at just a few places along the edges of the cuts in a leaf, as shown by the absence of brown colour: just at these places and at these only, as we have photographs to prove, the occlusion and abscission is very long delayed or may not take place at all.

We conclude therefore that where the factor of excessive dryness does not come in, the reaction of the leaf is directed against its connexion with the dead cells, and not against the free communication of its interior with the open air. Speaking, teleologically, the leaf is presumably protecting itself against the risk of infection which might get a start in dead cells which are kept moist by diffusion from living ones. The cases in which abscission follows fatal local heating without destruction of tissue also point to the same explanation.

When leaves freely cut open are left exposed to the dryness of the summer atmosphere, cells at the edge are soon killed off by natural drying, and we afterwards become unable to say which factor it is that provokes the subsequent reaction.

(3) Another problem lies in the causational difference between periderm-formation and abscission. Both processes seem to arise at corresponding spots in the line of occlusion, and both start by division of a more or less definite line of cells into daughter-cells. What are the factors that decide whether these cells shall dissolve the middle lamella between them, round off and separate, or whether they shall remain united as a phellogen and a first layer of cork?

The relative dryness of the surrounding air appears to be the essential cause, but we do not know whether isolation of the leaves from the parent plant has any effect. Many observers have noted that dryness promotes cork-formation in various cases, and Massart ${ }^{1}$ showed ingeniously that wounds opening to the atmosphere provoke more reaction than similar ones opening only internally into the natural hollow of a herbaceous stem, and also that only the layers exposed to external air became suberized. Massart ${ }^{2}$ also quotes some very suggestive but inverse observations as to the effect of

1 Massart, loc. cit., p. 46, Figs. 48-50.

${ }^{2}$ loc. cit., p. $5^{8}$. 
prolonged exposure to damp air on parts that normally form only cork. Thus in damp air the lenticels of Sambucus will grow out into tufts which consist of long multicellular filaments produced by the underlying phellogen; and even the phellogen under the leaf-scars on branches of Populus may react in the same way, although many layers of cork have been previously produced by it. The intumescences on Hibiscus, worked out by Miss Dale ${ }^{1}$, seem to belong to the same category in their causation.

This stimulation of a phellogen to grow out into filaments seems somewhat analogous with the stimulation of a meristem, so that the sister-cells become turgid and tend to round off from one another as in abscission. As soon as an abscissionline is formed in a dry atmosphere the parts of the leaf cut off outside it dry up, and so the line appears to have arisen close to the dead patch and not back in the sound tissue as it has done in reality.

(4) The distance from the lesion at which the reaction takes place seems to be constant for a given amount of injury, as the photographs all show, and to be further back the greater the killed area, but other factors also come in, as with the leaf in Text-Fig. 7. A curious case is given by Massart ${ }^{2}$ in which a reaction takes place at several centimetres from the seat of the injury. If an internode of Impatiens Sultani be cut through at the top no change takes place there, but a reaction takes place at the very bottom of the internode, where abscission takes place-as in leaf-fall-and the whole internode is thrown off. Also with many leaves, if the midrib be destroyed, the leaf becomes cut off at the normal position at the base of the petiole and a leaf-scar is formed there.

(5) Finally, the addition of the new phenomena which we have described to the previous stock of known reactions to traumatic lesions complicates very much the attempt to distinguish definitely between callus and wound-cork. Frank ${ }^{3}$ defines wound-cork as being formed by the passage of pre-

1 Dale, Philos. Trans. Roy Soc., vol. 194, p. 163, 1901.

${ }^{2}$ loc. cit., p. $6 \mathrm{r}$.

3 Frank, loc. cit. pp. 59, 60. 


\section{Blackman and Matthaei.-Traumatic Stimulation.}

existent cells directly into cork-cells by a renewal of meristematic activity, and wound-callus, on the contrary, as arising by an apical growth in the direction of the wound, taking place in the underlying cells and leading to the formation of unseptate tubes or rows of cells, which form a scar at the wounded surface.

Massart ${ }^{1}$ considers this distinction not to be strictly applicable to leaves, as growth-a callus character-is nearly always combined with the regular wound-cork formation.

That there should be a third alternative in the formation of an absciss-layer, determined merely by difference in external conditions, suggests that all these processes are conditional variations of the fundamental reaction to a traumatic stimulus which is directed to breaking the continuity of organization between the dead and the living cells.

1 Massart, loc. cit., p. 53.

\section{EXPLANATION OF PHOTOGRAPHS IN PLATE XXIX.}

\section{Illustrating Dr. Blackman's and Miss Matthaei's paper on the Reaction of Leaves to Wounds.}

The plate gives reproductions of six natural-sized photographs taken from the living leaves.

Figs. I, 2 are from one leaf showing the collective treatment of dead areas that are close together. Fig. I is an early state, but in Fig. 2 the process is nearly complete and the piece is hanging.

Fig. 3 is a late stage in the abscission of circular dead patches. The inner bole in each spot has been punched out and the outer concentric ring of separation is the work of the absciss-layer. The rings thus cut out are mostly still attached at one point.

Figs. 4,5 are from the same leaf; showing firstly the stage at which the occlusion-line is visible running round each brown area of dead cells, and secondly the final state in which all the pieces have been exfoliated and the new edges have finished growing.

Fig. 6 shows a leaf with two killed areas in the shape of longitudinal strips. This is in an intermediate state between those of the first and second figures and the pieces to be exfoliated are not quite free yet. 


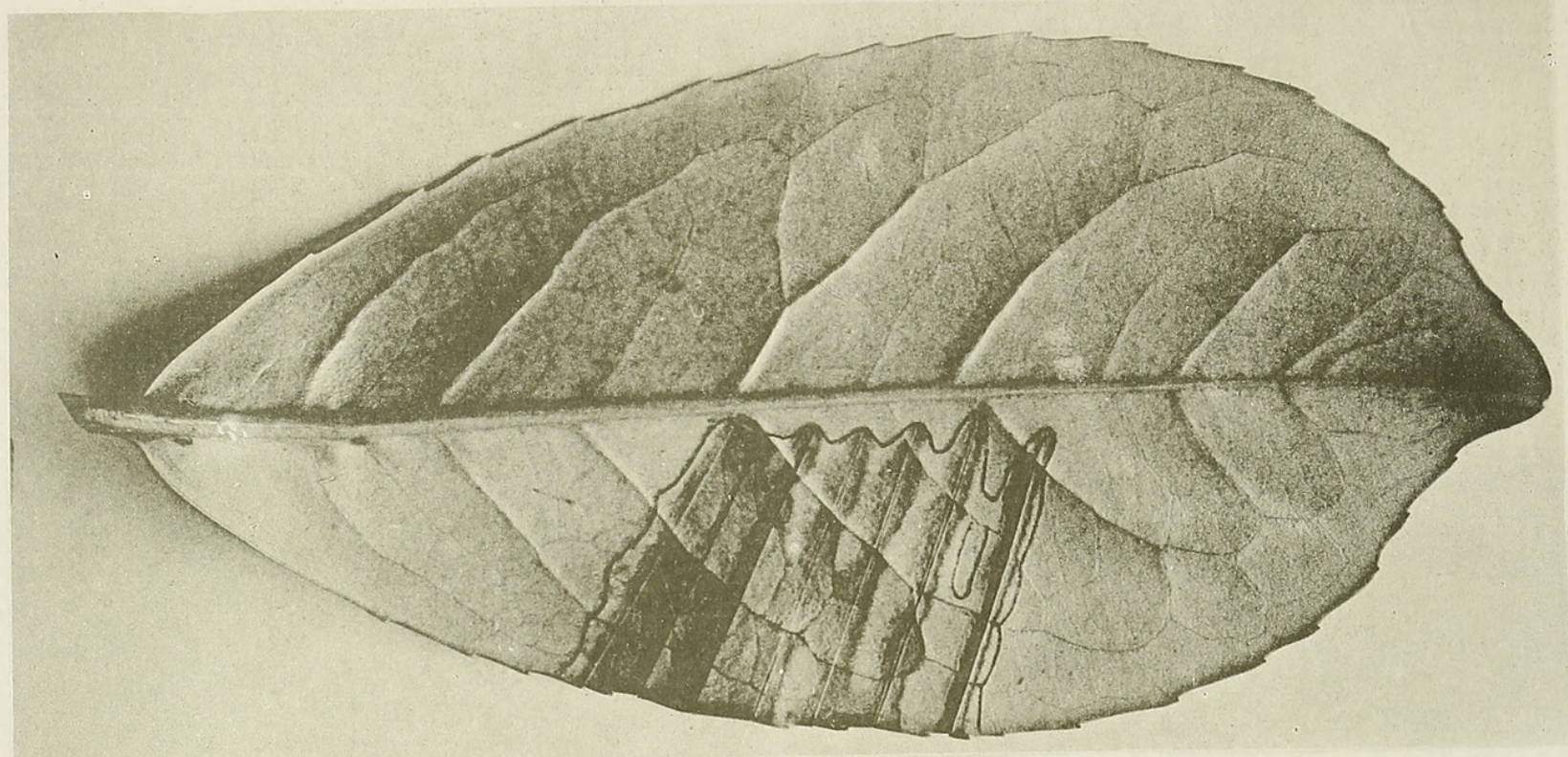

FIG. -

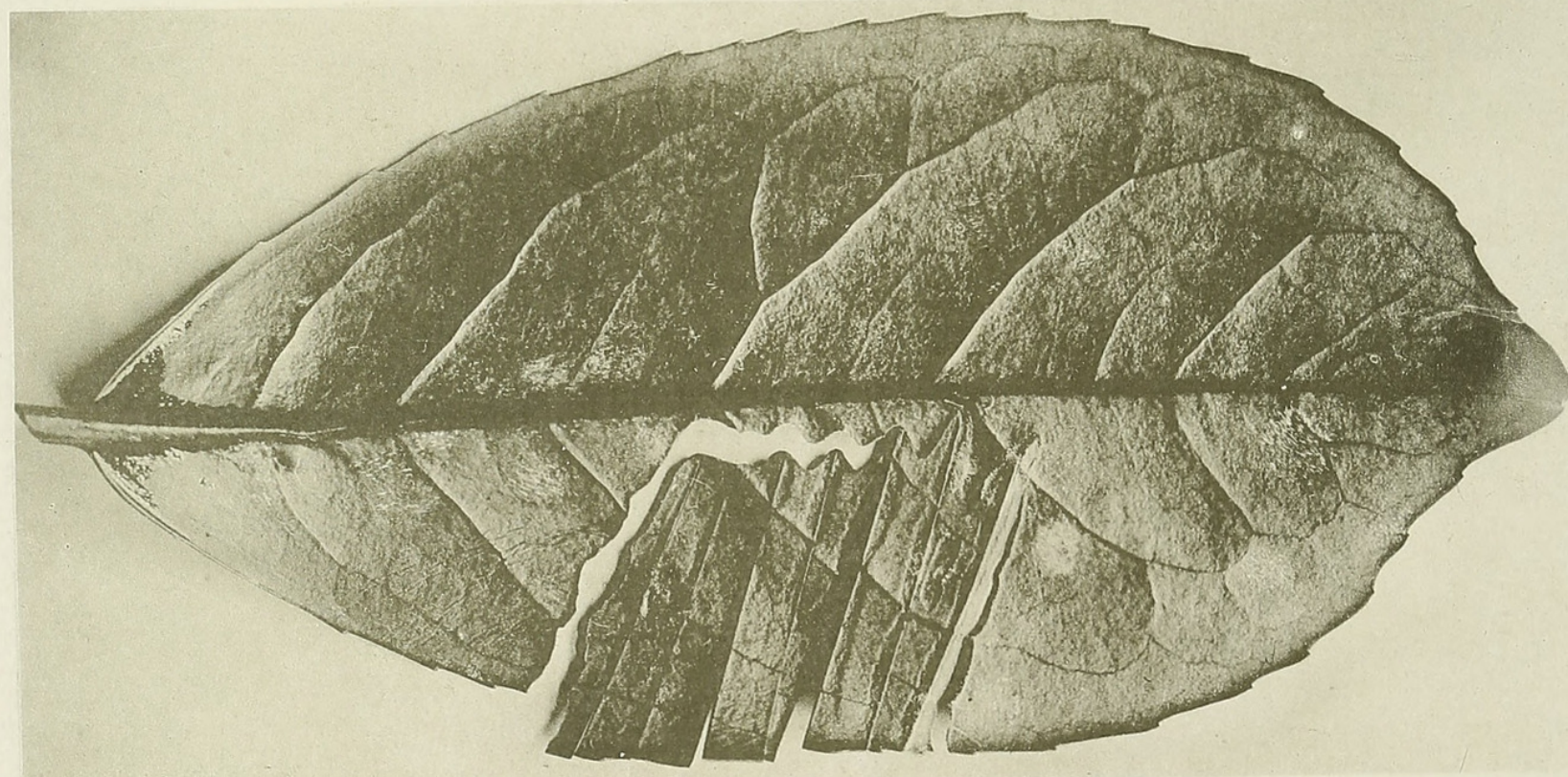

FlG. 2

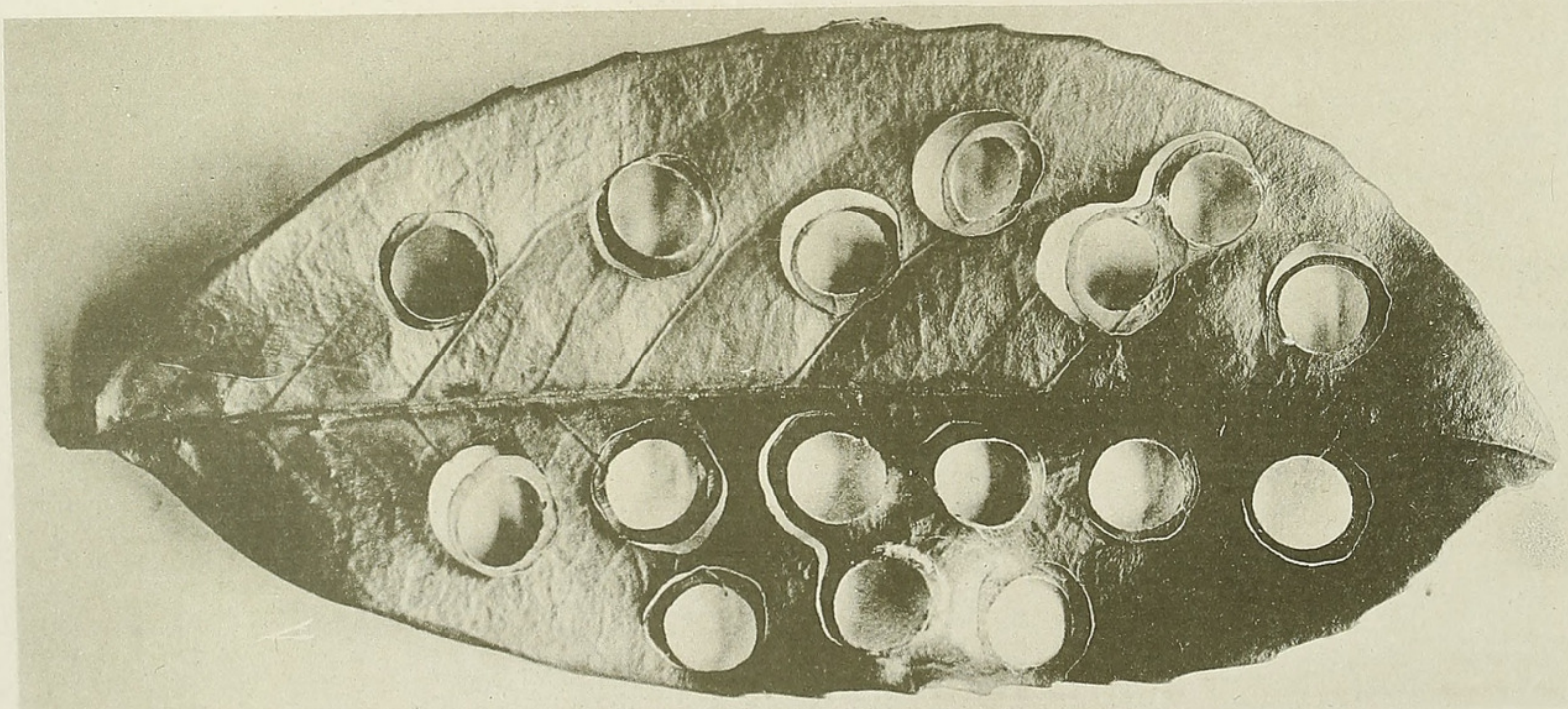

FIG. 3

BLACKMAN AND MATTHAEI - 


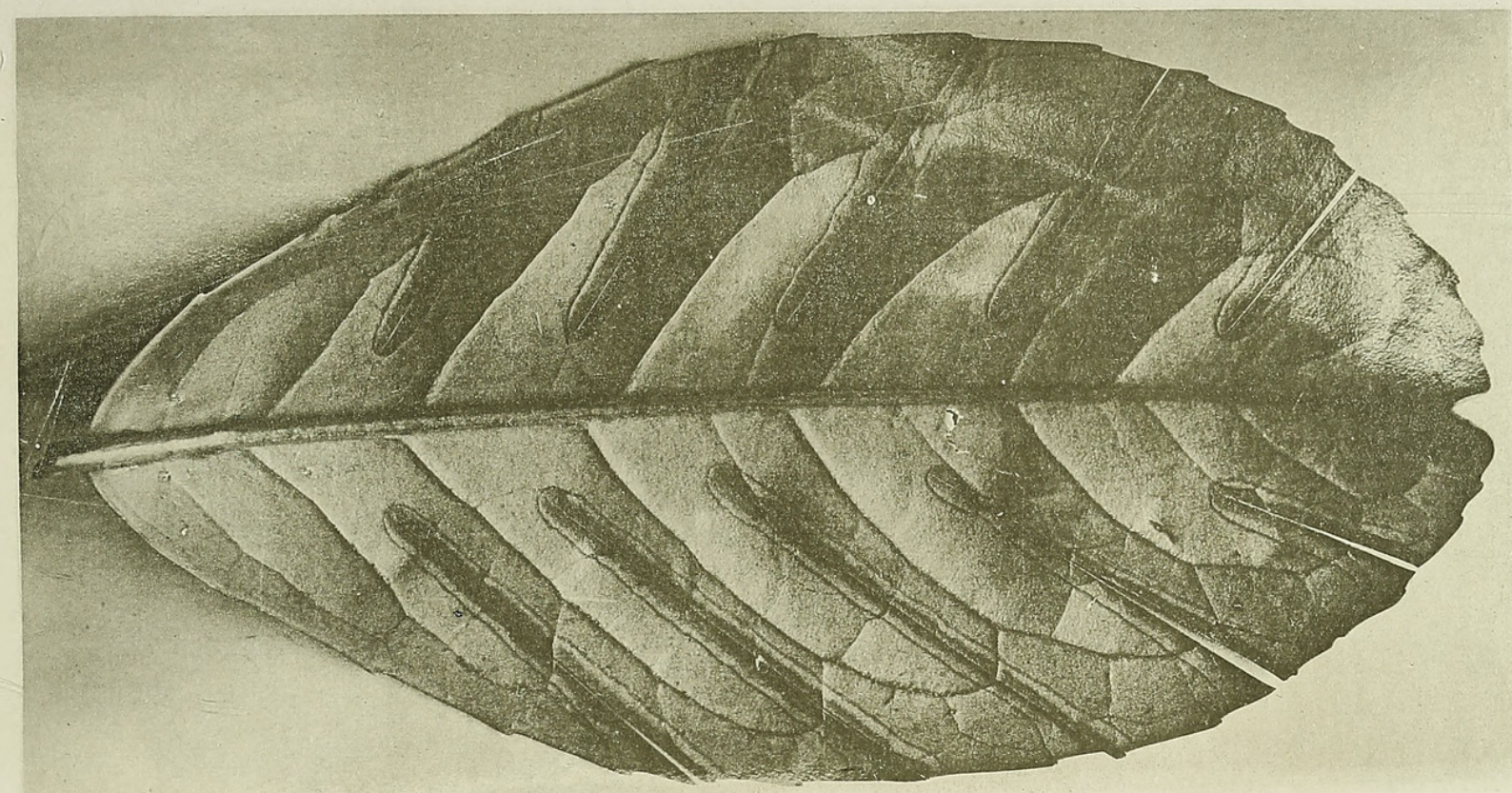

FIG. 4

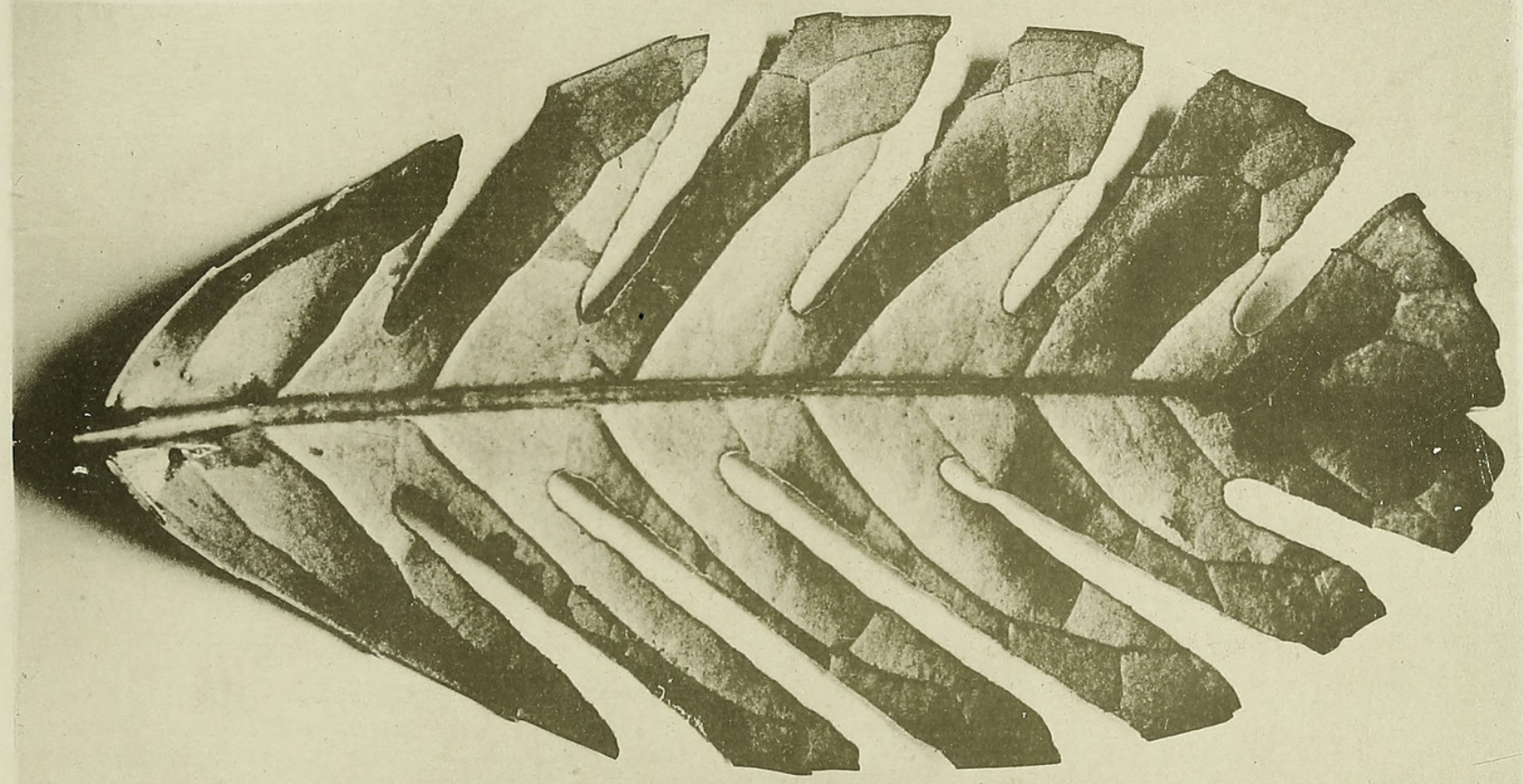

FIG. 5

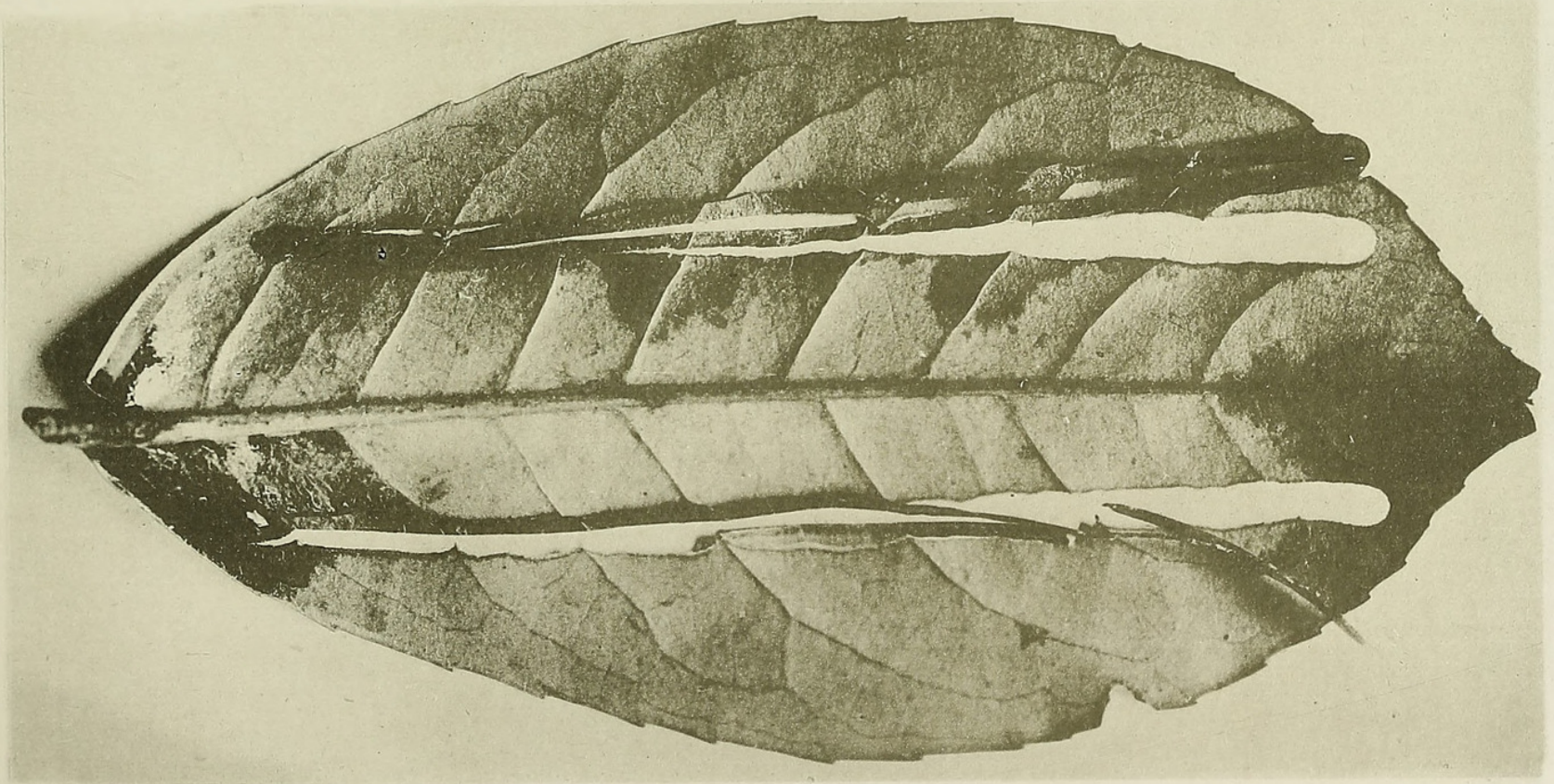

FIG。 6 

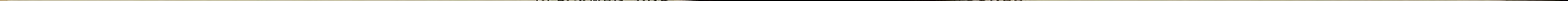


\section{$2 \mathrm{BHL}$ Biodiversity Heritage Library}

Blackman, Frederick Frost and Howard, Gabrielle L. C. 1901. "On the reaction of leaves to traumatic stimulation." Annals of botany 15, 533-546. https://doi.org/10.1093/oxfordjournals.aob.a088833.

View This Item Online: https://www.biodiversitylibrary.org/item/236929

DOI: https://doi.org/10.1093/oxfordjournals.aob.a088833

Permalink: https://www.biodiversitylibrary.org/partpdf/318637

\section{Holding Institution}

Smithsonian Libraries

\section{Sponsored by}

Biodiversity Heritage Library

\section{Copyright \& Reuse}

Copyright Status: Not in copyright. The BHL knows of no copyright restrictions on this item.

This document was created from content at the Biodiversity Heritage Library, the world's largest open access digital library for biodiversity literature and archives. Visit BHL at https://www.biodiversitylibrary.org. 